\title{
The Impact of Organizational Factors Based on Technology-Organization-Environment (TOE) Framework on Practical Levels and Characteristics of Audit Analysis and Internal Audit Performance
}

\author{
Mehdi Moradi and Ehsan Rahmani Nia
}

\begin{abstract}
The purpose of this study was to investigate the impact of organizational factors based on the technologyorganization-environment (TOE) framework on the applied levels and characteristics of audit analysis and internal audit performance. This study examined the factors that influence the use of audit analytics after applying these analyzes, as well as whether the use of audit analytics improves internal audit performance. This is a descriptive-correlational study. The statistical population of the study consisted of: Certified Public Accountants working in the Audit Organization, Institutions of Public Accountants Society using Cochran formula, 150 individuals were selected as sample. Data gathering tool was a 21-item researcher-made questionnaire whose validity was confirmed by face and structural methods and the reliability of the questionnaire was confirmed by Cronbach's alpha. Data analysis was performed using Amos 22 software and structural equation modeling method. The findings show that the complexity of information technology (IT), technology competency, managerial support and professional assistance have a positive and significant effect on the application and software level of audit analytics. The size of the organization and auditing standards have a significant and positive effect on the performance of the audited analysts. Functional auditing has a positive and significant effect on the level of (software) auditing analytics, and functional auditing and auditing analysis have a significant positive effect on internal audit performance.

Index Terms-Audit Analysis, Adopting Audit Technology, Technology - Organization - Environment (TOE)
\end{abstract}

\section{INTRODUCTION}

The use of analytical methods in independent auditing has been recognized as one that improves auditing efficiency, and has always been emphasized by professionals and academics $[1,2,3,4]$. Analytical methods are one of the best methods of auditing and require the evaluation and analysis of data and always have the advantage of performing analytical methods in which financial and non-financial information are considered together. Analytical methods are also unlike many holistic audit methods. And it yields significant and significant results that can be included in the audit report [5]. Audit analysis is performed as the science of analyzing patterns, identifying deviations, and extracting useful information from underlying data or audit issues through analyzes, modeling, and mapping for the purpose of planning or conducting audits [6].
The important point is that applying analytical methods based on the fact that large-scale sampling in large corporations cannot account for the reasonable retention of audit risk because auditors, using all their evaluations, will inevitably be judged in applying sampling techniques. The capture that results in the elimination of most of the transactions. The idea of using all available data to lose the bulk of the data through sampling illustrates the importance of applying technology to the audit profession. Technology makes it possible to identify and report unusual and unusual aberrations by analyzing the data and executing the correct patterns and will require all the transaction data for this purpose. Moving along this path requires many factors, some of which have been tried in this research to test to what extent these factors have reached sufficient maturity.

So far, several researches have been carried out on the application of analytical methods in Iran, focusing mainly on the use of analytical methods in the planning, audit and overall review stages. However, there is no research that examines the factors and determinants affecting the use of audit analytics and examines the impact of the dimensions of auditing analysis including the level of application and specificity on internal audit performance, the impact of organizational, environmental and technology factors on audit analysis. Therefore, in this study, considering the importance of auditing analysis in the audit process, it deals with the issues raised.

Audit software developers have developed extensive analytical tools to improve audit quality and reliability. Public data analysis software packages are also used in the audit process. Using audit analytics not only increases operational efficiency by reducing costs [7], but also helps to quickly detect fraud and deviations thereby providing a higher level of assurance [8].

Internal Audit As defined by the American Association of Internal Auditors, the Board of Directors is an independent consulting and assurance activity for the Board of Directors to play a role in improving the organization's operations toward creating value. Given this definition and given the trend of companies in expanding their activities and their desire to expand their business and to rely more and more on internal audit information technology, it is necessary to adopt 
a new approach in carrying out their mission. In such an environment, value creation for the organization, which is the ultimate goal of internal auditors, can only be achieved when internal auditing is in line with the growth of technology companies.

Accordingly, first, internal auditors have broader tasks and missions than even independent auditors, including examining operational and financial issues, the effectiveness of governance processes, fraud risk assessment $[9,10]$. Therefore, internal auditors should focus more on the need to use audit analytics to perform their duties in an effective and efficient manner. Second, internal auditors often have more access to financial and business data, which can be used with audit analytics to quickly detect errors and frauds, allowing them to more flexibly examine various audit analysis tools. Not surprisingly, analysis is expected to become the professional capability of internal auditors [11], and many scholars have made great efforts to integrate analytics into internal auditing. For example, Thiprungsri and Vasarhelyi [12] developed analytical models to identify people's illegal claims for disability insurance, and Kim and Vasarhelyi [13] conducted analyzes to identify potential frauds in the electronic money transfer process. Jans et al. [14] show how internal auditors can use the event reporting process to apply a new type of analytical method to identify and control deficiencies.

Although internal auditors are acutely aware of the importance and value of auditing $[15,16]$, surveys show that most companies do not fully utilize audit analytics [17,16]. Many auditors are unable to effectively use audit analytics in their business processes and use it only in stereotypes. While some studies, attempted to identify barriers to acceptance of audit analysis, limited academic research has examined the extent of actual use and the factors that lead to differences in use and use. Have been investigated.

The purpose of this study is to investigate the organizational factors that influence the application of audit analysis after their adoption in both dimensions of utilization and quality. And whether using analytics improves internal audit performance. Previous studies have examined the use of technology in the internal audit process, including computerbased audit methods and tools (CAATs), audit continuity. However, compared to computer-based audit methods and tools (CAATs), auditing analysis requires the university's and auditor's specialty. Which leads to new challenges. For example, audit analytics as compared to computer-based audit methods and tools (CAATs) typically involves advanced statistical techniques or data analysis tools (such as data mining); most auditors have limited knowledge of analytical methods. Therefore, understanding these techniques can be a challenge. Failure to fully understand audit analytics may result in errors in the use of analytical methodology as well as inaccurate interpretation of the results. In addition, audit analyzes are usually performed with large amounts of data that can increase the information burden and thus affect auditors' decision-making processes. The difficulty of extracting useful information from large amounts of data can hinder auditors' use of analytics. Understanding the factors that influence the use of audit analytics can provide insights for executives, legislators, and creators of audit analytics software.

In this research, using the Technology-OrganizationEnvironment (TOE) model, we will investigate the factors affecting the application of audit analysis and the impact of audit analysis on improving the performance of internal audit processes. According to the theoretical background, in this study, the distinction and application of audit analytics at two levels of application and specificity level have been investigated. The applied level of audit analytics indicates the extent to which auditors use audit analytics software. For example, when software is capable of auditing analysis in many audit processes, the applied level of audit analytics appears to be high. The second area under consideration is feature-level audit analytics, which is a combination of the metrics that some audit analytics techniques use, for example, summary, regression, Bannford's law, etc., and the frequency of use. It is assumed that technology adequacy, technology complexity, enterprise size, managerial support, standards, and professional assistance will affect the application of audit-level analytics. It is therefore assumed that at the applied level, professional assistance, and technology adequacy will have a positive effect on the use of featurelevel analytics. Finally, the use of audit analytics at both levels improves internal audit performance. Therefore, the purpose of the present study is to investigate the effective organizational factors on the application of auditing analytics based on new technologies and also to investigate the impact of audit analysis on internal audit performance.

The triple importance of this study can be stated as (1), this is the first study to investigate the factors affecting the use of audit analytics in the country, and to examine simultaneously the impact of audit analysis on audit performance. The results of this study provide important insights and insights for software executives, legislators, and makers and marketers to potentially facilitate the integration of audit analytics into internal auditing. (2), new structures are proposed to measure the use of audit analytics. In the conceptual model of this research, auditing analyzes are examined from both an operational and a specific level. This has only been addressed in external studies. (3) This study examines the factors affecting the use of audit analytics from an organizational perspective. There are various innovation acceptance theories to help managers, decision makers, and researchers plan, execute, and review their work and the timing of adoption of new technology. Among the various acceptance theories, some of the most popular are the technology acceptance model, acceptance theory and technology.

But given that these theories are focused on the individual level, and given the fact that the adoption of information technology in accounting and auditing requires the attention and willingness of all levels of organizational, technology, and external factors that rely on internal audit performance. Information technology has an impact, unlike previous theories, Tornatzky \& Fleischer proposed framework focuses on organizational levels. This theory defines the acceptance and implementation of technological innovations by companies influenced by technological, organizational, and external contexts. Therefore, the most important feature of the present study can be considered the first use of this 
framework in the audit study. As a result, this research as a model helps audit firms identify specific factors and barriers to implementing new technologies for performing audit analyzes.

The main beneficiaries of this research are regulatory bodies such as the central bank, stock exchange and auditing agencies to implement measures to advance data-based auditing as well as companies and organizations to improve and enhance the results of their research in their organizations. The implementation of the audit will be based on data analysis. Other universities and institutes of higher education, auditing institutes, professional associations, including the Iranian Society of Certified Public Accountants, the Association of Chartered Auditors and others will be among the other groups that use this right.

The topic of information technology and its applications in the audit analytics system is in its infancy, and due to research and theoretical backgrounds in the country, has not been operational, in this study for the first time using the technology adoption model (TOE). A comprehensive model of organizational factors, it will be addressed to identify organizational factors in three areas of technologyorganization-environment affecting internal audit functions. And this research was conducted for the first time in the auditing institutes, members of the Society of Certified Public Accountants and the Audit Organization in Tehran. Also, with a more comprehensive and detailed look at the topic of audit analysis, it was examined from both qualitative and quantitative aspects in a conceptual model. Structural equation modeling was used to analyze this model, which made the research and analysis of this research innovative.

Based on the conceptual model of research based on the TOE framework, and based on the studies of 29. The conceptual model is drawn to evaluate the use of audit analyzes. On the left side of the model predicts the use of audit analytics as influencing factors in utilizing audit analytics. The right side of the figure also shows the improvement in the performance of the internal audit process because of this technology.

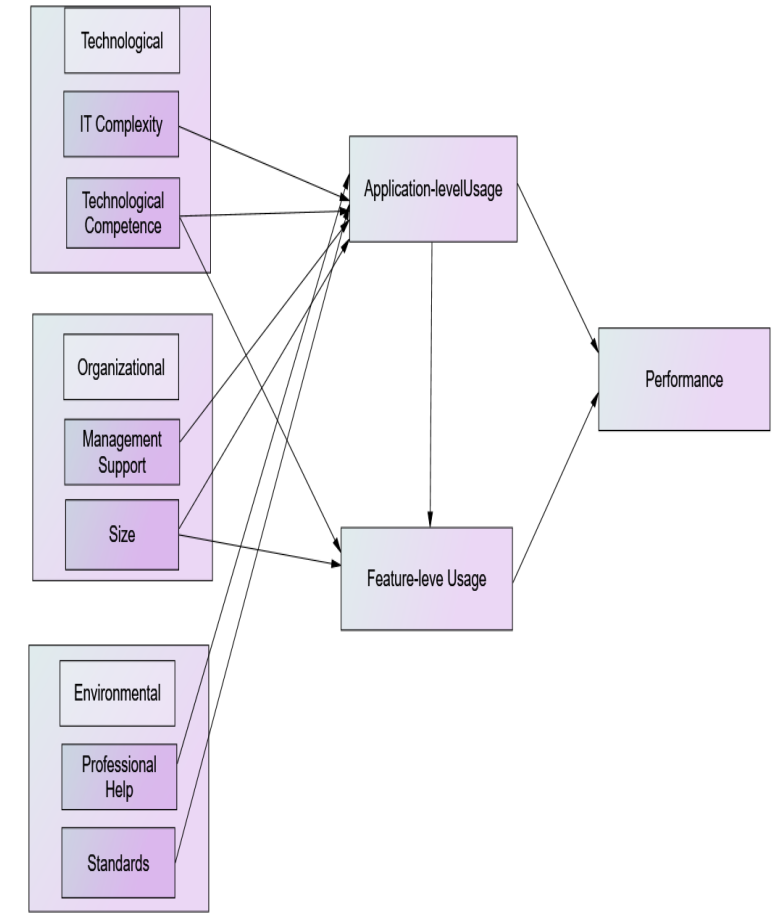

Fig 1. Conceptual Model of Research

Research hypotheses

1. The complexity of IT has an impact on the software level of audit analytics.

2. Organizational technology competence affects the software level of audit analytics.

3. Managerial support in organizations affects the software level of audit analytics.

4. The size of organizations affects the software level of audit analytics.

5. The use of professional assistance in organizations affects the software level of audit analytics.

6. The use of professional assistance in organizations affects the software level of audit analytics.

7. Auditing standards affect the software level of audit analytics.

8. Software level audit analysis affects attribute level) Audit analytics.

9. 9 Organizational technology competence affects the level of specificity of audit analytics.

10. The use of professional assistance in organizations affects the level of specificity of audit analytics.

11. The software level of audit analytics has an impact on internal audit performance.

12. The nature of audit analytics affects internal audit performance.

\section{RESEARCH METHOD}

The present study can be considered as a purpose-based, applied and descriptive-survey method. Finally, by expanding and developing the theoretical and conceptual foundations of this research we can conceive of the long-term applications of the present research. The participants in the present study, or in other words the statistical population of the study, are members of the Iranian Society of Certified 
Accountants. Pursuant to Article 4 of the Code of Conduct for the Certification of Certified Public Accountants and the Selection of Those, the Certified Public Accountants, who shall designate themselves entirely to statutory auditing or other services considered to be part of the duties of the official accountant and having other occupations, including Not obliged (except for part-time teaching at universities and higher education institutions), they are called official accountants, in this case they will be recognized as nonemployed accountants (Iranian Association of Accountants, 2009). He is also the manager and internal auditing officer of the stock exchange and cross-border companies. All companies that were on the list of listed companies by the end of September 1977 were questioned. In the present study, a non-probable, purposive or judgmental sampling method was used to distribute the questionnaire and try to be representative of the community and have easy access to the sample population. The sample size was calculated using Cochran formula. In the absence of answering some of the questionnaire questions and consequently eliminating them in the analysis phase, 150 questionnaires were prepared and distributed among the employed official accountants.

The main tool for data collection in this study is questionnaire. At the beginning of the research questionnaire, questions were collected in order to obtain demographic characteristics, including general characteristics of the individuals who participated in this study. Then, the subjects were asked how to answer each question of the research instrument. The second part of the questionnaire consists of 21 questions with a total of 21 items, and all questions are asked on a seven-point Likert scale ranging from never to ever numerically valued 1 to $7(1=$ Never, $2=$ Rarely, $3=$ Never, $4=$ sometimes, $5=$ usually, $6=$ most often, and $7=$ always).

The TOE Technology-Organization-Environment Model Structure questions have been formulated based on Li, Dai, Gershberg, and Vasarhelyi with changes to fit the questions with public and private accounting organizations. The conceptual model is adapted from Li, Dai, Gershberg, Vasarhelyi. The researcher, referring to the professors, experts and experts, has made the required modifications and edits and finalized the questionnaire and in the content validity method, the validity of the measuring instrument was confirmed by the comments of relevant experts. Cronbach's alpha reliability was used to assess the reliability of the research questionnaires. Therefore, in order to measure the reliability and reliability of the questionnaire

TABLE 1: RESULTS OF CRONBACH'S ALPHA TEST OF THE RESEARCH VARIABLES FOR 30 SAMPLES

\begin{tabular}{|c|c|c|}
\hline $\begin{array}{l}\text { Cronbach's } \\
\text { alpha value }\end{array}$ & items & Component \\
\hline .770 & 4 items & $\begin{array}{l}\text { Application- } \\
\text { levelUsage }\end{array}$ \\
\hline .789 & 4 items & $\begin{array}{l}\text { Technological } \\
\text { Competence }\end{array}$ \\
\hline .758 & 3 items & Standards \\
\hline .714 & 4items & Performance \\
\hline .715 & 3 items & IT Complexity \\
\hline .748 & 3 items & Feature-levelUsage \\
\hline- & Corporate Information & Size \\
\hline- & Corporate Information & IT Complexity \\
\hline
\end{tabular}

Since the value of Cronbach's alpha is above 0.7 for all research variables, it can be said that the questionnaire has acceptable reliability. Descriptive statistics were used to analyze the demographic data and then data were analyzed using SPSS and AMOS software.

\section{FINDINGS AND DISCUSSIONS}

Demographic characteristics of the statistical sample show that out of 150 samples, $111(74 \%)$ of the respondents are male and $39(26 \%)$ are female. So it turns out that most respondents belong to the male group with $74 \%$. The majority of respondents belonged to the age group of 40-36 years (45\%) comprising $18(12 \%)$ postgraduates, 57 (38\%) undergraduates and $75(50 \%)$ postgraduates and above. Therefore, most respondents appear to be postgraduate and above $80 \%$. $69(46 \%)$ of the respondents have a history of operational audit and $81(54 \%)$ of the respondents have no operational audit history. That $86(57.7 \%)$ of the respondents were or will be performing operational audits in companies that have been or are not, and $64(43.3 \%)$ of the respondents were not performing operational audits in companies that were or are or be. Work experience $26(17.8 \%)$ under 10 years, $49(33.6 \%)$ between $11-15$ years, $34(23.1 \%)$ between 16-20 years, $17(11.2 \%)$ Between 21 and 25 years, 15 $(10.2 \%)$ were between 26 and 30 years, and finally $9(6.1 \%)$ were older than 31 years.

Kolmogorov-Smirnov (KS) test was used to check the normality of the data. In this test, if the significance level is less than 0.05 , the null hypothesis is rejected and if the significance level is more than 0.05 , the hypothesis is accepted. The results of factor normality test are presented in Table 2 . 
TABLE 2. DESCRIPTIVE INDEX AND KOLMOGOROV-SMIRNOV TEST FOR CHECKING THE NORMALITY OF THE VARIABLE (N: 150)

\begin{tabular}{ccccc} 
Kurtosis & Skewness & Std. & Mean & Variable \\
\hline .215 & -.853 & 3.617 & 17.93 & $\begin{array}{c}\text { Application- } \\
\text { levelUsage }\end{array}$ \\
\cline { 4 - 5 } 1.274 & -.912 & 2.211 & 11.09 & $\begin{array}{c}\text { Management } \\
\text { Support }\end{array}$ \\
.852 & -1.028 & 2.412 & 10.71 & $\frac{\text { Standards }}{$\cline { 3 - 4 }} \\
-.293 & -.700 & 2.596 & 14.65 & $\begin{array}{c}\text { Professional } \\
\text { Help }\end{array}$ \\
.343 & -.786 & 3.033 & 14.37 & Performance \\
-.042 & -.605 & 2.406 & 10.87 & $\begin{array}{c}\text { Feature- } \\
\text { levelUsage }\end{array}$ \\
\hline
\end{tabular}

In the present study, SEM was used to test the hypothesis of the hypothesized relationships. The proposed model in this study has two structural and measurement parts. The structural section focuses on the causal effects of exogenous variables on endogenous variables. The measurement section shows how the markers (indicators) measure the presumed structures.

Confirmatory factor analysis is used to determine the validity of the indices of each variable and the difference between the variables. If the items have an operating load less than 0.5 , the model can be modified by removing those items. Also, if the significance level of each item is higher than 0.05 it can also be interpreted that the item cannot be a suitable measure for the variable and should be excluded from the model. Also, the factor loadings of the items are higher than 0.3. Since in this model the items Q1-Q2-Q18-Q20 have a significant level greater than 0.001 and the factor loadings of items are less than 0.3. As a result, they are removed for model accuracy. And the work goes on without these items.

After testing the hypotheses using AMOS path analysis coefficients with maximum likelihood method, related indices are used in this section to evaluate the tested model.

TABle 3- Structural MODELing Suitability IndiCATORS OF THE

\begin{tabular}{|c|c|c|}
\hline \multicolumn{3}{|c|}{ PROPOSED MODEL } \\
\hline $\begin{array}{l}\text { Standard } \\
\text { value }\end{array}$ & value & INDEX \\
\hline $\begin{array}{l}0.08 \text { and } \\
\text { less }\end{array}$ & 0.072 & RMSEA \\
\hline $\begin{array}{c}0.05 \text { and } \\
\text { less }\end{array}$ & 0.049 & RMR \\
\hline Less than 5 & 5.394 & $\chi^{2} /$ DF (CMIN) \\
\hline At least 0.9 & 0.921 & NFI \\
\hline $\begin{array}{c}\text { Less than } \\
0.5\end{array}$ & 0.432 & PNFI \\
\hline At least 0.9 & 0.921 & CFI \\
\hline At least 0.9 & 1.000 & GFI \\
\hline At least 0.9 & 0.915 & RFI \\
\hline At least 0.9 & 0.928 & IFI \\
\hline At least 0.9 & 0.936 & AGFI \\
\hline $\begin{array}{l}\text { Less than } \\
0.5\end{array}$ & 0.502 & PGFI \\
\hline
\end{tabular}

As shown in Table 3, according to the fit indices, in particular the chi-squared ratio of the degree of freedom equal to 2,432 (criterion less than 8), goodness of fit index (GFI) equal to 0.001, adjusted goodness index (AGFI 0.891, comparative fitness index (IFI) 0.928, incremental fitness index (CFI) 0.921, standardized fit index (NFI) 0.921 and root mean square error of approximation (RMSEA) equal 0.053 , which indicates that the proposed model has a good fit.
Table (7) shows the causal analysis findings using the structural equation model to test the research hypotheses. In AMOS software, the hypothesis is rejected or confirmed with $\mathrm{CR}$ and $\mathrm{P}$. If the $\mathrm{CR}$ index is higher than 1.96 and $\mathrm{P}$ is less than 0.05 it indicates the causal relationship between the variables and the hypothesis is confirmed. The results of this model are presented in Table (4). According to Table (4), it can be said that the assumptions have been confirmed.

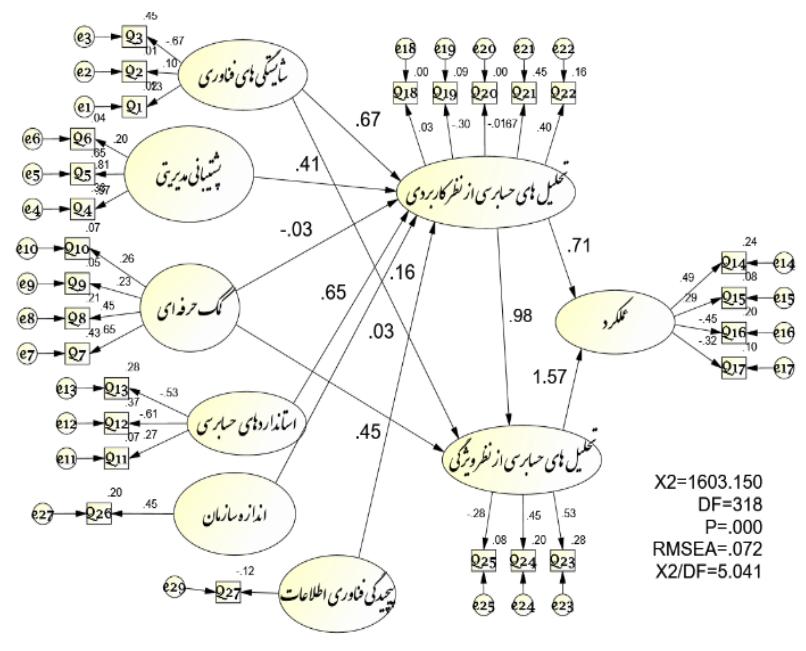

Fig 2: The result of the research hypotheses

TABLE 4 SUMMARIZES THE STANDARD COEFFICIENTS, T-STATISTIC AND HYPOTHESIS RESULT

\begin{tabular}{|c|c|c|c|c|}
\hline $\mathrm{P}$ & SReg & The dependent variable & Relationships & $\begin{array}{l}\text { independent } \\
\text { variable }\end{array}$ \\
\hline .035 & .770 & Application-levelUsage & $<---$ & $\begin{array}{l}\text { Technological } \\
\text { Competence }\end{array}$ \\
\hline$* * *$ & .389 & Application-levelUsage & $<---$ & $\begin{array}{c}\text { Management } \\
\text { Support }\end{array}$ \\
\hline .045 & .158 & Application-levelUsage & $<---$ & $\begin{array}{c}\text { Professional } \\
\text { Help }\end{array}$ \\
\hline .003 & .614 & Application-levelUsage & $<---$ & Standards \\
\hline .008 & .115 & Application-levelUsage & $<---$ & Size \\
\hline .422 & .448 & Application-levelUsage & $\begin{array}{ll}<--- \\
\end{array}$ & $\begin{array}{c}\text { IT } \\
\text { Complexity } \\
\end{array}$ \\
\hline$* * *$ & 1.007 & Feature-levelUsage & $<---$ & $\begin{array}{l}\text { Application- } \\
\text { levelUsage }\end{array}$ \\
\hline .005 & .433 & Feature-levelUsage & $<--$ & $\begin{array}{c}\text { Professional } \\
\text { Help }\end{array}$ \\
\hline .015 & .184 & Feature-levelUsage & $<---$ & $\begin{array}{l}\text { Technological } \\
\text { Competence }\end{array}$ \\
\hline .004 & 0.645 & Performance & $<---$ & $\begin{array}{c}\text { Feature- } \\
\text { levelUsage }\end{array}$ \\
\hline .012 & .802 & Performance & $<---$ & $\begin{array}{c}\text { Application- } \\
\text { levelUsage }\end{array}$ \\
\hline
\end{tabular}

\section{CONCLUSION}

This study examined the factors that influence the use of audit analytics after applying these analyzes, as well as whether the use of audit analytics improves internal audit performance. Effective factors were explored from the organizational perspective rather than the individual level to fill the gap in previous literature. By adopting the TOE framework, several structures were assumed to facilitate the level of quality and applicability of audit analysis, and to examine whether the use of audit analysis improves the performance of the internal audit process, paid.

The results of the first hypothesis showed that the complexity of information technology (IT) has a positive effect on the software level of audit analysis. 
Information technology auditing is also affected by a series of factors that each of these factors somehow influence this quality. Therefore, companies engaged in information technology auditing should examine each of these sub-factors and identify ways to succeed in each of these dimensions and ultimately enhance the quality of financial reporting. Information Technology Audit is one of the most important factors in improving the quality of internal audit and it is observed that information technology improves the quality of internal audit by affecting the auditor's independence, thus helping the audit team to perform its operations. Independently using information technology, they are more interested in the notion that corporate auditors are professionals who expect the social responsibility of protecting their business owners and other stakeholders from any mismanagement and distortion by managers. The river is not only economically self-sufficient recent advances in information technology and the risk of manipulating information may outstrip the ability of the auditing profession and auditors may not be able to handle it. Auditors are one of the members of the financial reporting chain who are some kind of information user. In an electronic environment where financial reporting uses information technology, auditors will also be able to use this technology to handle, process and analyze massive amounts of information and to have timely, accurate and complete analysis of their data.

The results of the second hypothesis showed that the technology competence of organizations has a positive impact on the software level of audit analysis. Nowadays, technological advancements have enabled auditors to incorporate better and easier analytics tools into their audit practices to become an integral part of the audit process in the future and to transform auditing processes into better analytics. For IT professionals, auditors need to have reasonably good IT capabilities so that they can accurately perform audits and lack of knowledge can negatively impact performance and quality. Have the work done.

Technology competencies are comprised of two parts: IT infrastructure and IT professionals. IT infrastructure refers to the physical assets that a company owns that can be used to facilitate technology adoption. IT professionals are personnel who have the knowledge and skills to perform computer related tasks. Technology Shits are required to use audit analytics software. It is impossible to properly utilize audit analytics tools without the support of qualified technical personnel, which is due to the lack of these barriers to the proper implementation of computer-assisted CAATTs auditing tools and techniques [20,13] As previous research indicates that technology competence is a prerequisite for adopting technology innovation [19], it is expected that internal audit departments with more technology competencies are likely to be more prepared to use innovative technology. Use it in the audit process.

The results of the third hypothesis show that managerial support in organizations has a positive impact on the applied level of audit analysis. Managers 'or managers' commitment is the amount of management commitment and attention a company invests in innovative technology. Management literature shows that high level support plays a key role in the success of almost all programs in an organization [20]. Audit analysis is no exception. Audit analysis requires management to devote resources to purchasing analytics software, performing maintenance and auditor training.
The results of the fourth hypothesis showed that the size of organizations has an impact on the performance of auditing analysis. The results of the fifth and sixth hypotheses showed that professional assistance in organizations has a positive effect on the level and functionality of (audit) software analytics.

Technical skill and professional assistance are expected to influence the use of software-level audit analytics. Because advanced audit analytics tools are difficult to use and require more expertise, technical support will have a direct impact on advancing audit analytical skills. For example, Vasarhelyi et al., interviewed internal audit executives and found that training is essential in providing information technologybased knowledge to employees. Likewise, technology competence is the basis of the use of advanced analytical audit techniques. Companies with up-to-date IT infrastructure and skilled IT professionals are capable and likely to perform advanced audit analytics, while people with low technology competence may only be able to use key analytics tools. Audit in its simplest way.

The results of the seventh study showed that auditing standards affect the audit analysis in terms of application. Standards refer to the perceived level of encouragement of auditing standards to use audit analysis. While there is no mandatory requirement for the use of auditing analysis, professional bodies and guidance encourage the use of technology-based auditing and other data analysis techniques in performing internal auditing [21]. Companies facing different risks in their businesses and industries may have a different understanding of how stringent standards are in applying audit analytics. Therefore, it seems that in an organization, the standards of audit analytics are centralized, and the organization is forced to use new audit analytics tools to reduce the complexity and complexity of data.

The results of the eighth study showed that auditing analytics has a significant impact on the level of (software) auditing analytics. They are not each other. In addition, greater use of program-level audit analysis leads to a greater familiarity with audit software. Therefore, auditors who frequently use audit software, because of their confidence and familiarity, succeed in learning and using different audit analytics and gain skills. Therefore, there should be a positive relationship between the use of program-level audit analysis and the use of attribute levels.

The results of the ninth survey showed that the suitability of the technology of the organization influences the level of auditing analytics. In any organization, learning and individual and team skills need to be improved and effective. The more people acquire the skills they need, the more impact they will have on productivity, organizational development, behavior, and the like. Over the past fifty years, the advent of computer and communications developments has led to major changes in the various spheres of human life. Human beings have always used technology, and the human life record is replete with the invention of information and communication technologies, referred to as new or advanced technologies, which have had the greatest impact on human life. Technology development is one of the most important strategic decisions that management faces today in a global competitive environment. The increasing development of information and communication technology in the last decade has increased the competitiveness of organizations and the access to information technology has become the main factor 
for survival in this competitive environment. Experts have announced more radical changes that could transform the present period into the most fundamental period in human history.

Sun [22]. and Jasperson [23]. have both shown that users are curious about new features after adopting IT systems. While users initially only need a limited number of features, they eventually realize that a larger set of features is needed as they gain more experience [24]. Although greater use of software may not necessarily encourage the use of a broader set of audit analytics tools, it may help auditors to increase their confidence in using audit software. Compeau and Higgins [25] conducted an experiment showing that people who are confident in their ability to use the computer have higher expectations of computer use results and can actually perform better than people who have less confidence. Have, do.

The results of the tenth hypothesis study show that professional assistance in organizations has a positive effect on the level of audit analytics specificity. Discussion with internal auditors indicates that a major obstacle preventing the use of advanced audit analytics is the inability to obtain timely professional support. Ndubisi et al., [26] found that systems are more successful when it comes to technical support. Information about new features and products can also enhance the user's understanding of the software. Although software vendors offer audit analytics, online training and on-site training, the problem is only mitigated rather than eliminated. The high cost and limited time of training classes may limit their benefits and limit the specificity of work in training.

Given the fact that internal audit activities are performed in a dynamic management process and in a highly supportive environment, the internal auditor expects the senior management of the organization to take the first steps to support the internal audit process. Sarens \& Beelde [27], argue that the overall acceptance and understanding of internal audit in an organization strongly depends on the support it receives from senior management.

The results of the study of Hypothesis 11 showed that audit analysis had a specific effect on internal audit performance. These results are in line with the findings of Moghaddam maenavi [28], Khodami, \& Saeedi, [29].

With the current evolving environment, the ability to take full advantage of huge volumes of data, along with traditional trading data, provides new opportunities for senior financial managers to assess risk and increase their insights. The analytics tool will make the updates uninterrupted throughout the audit process as a result of which senior financial managers will gain a stronger and more insightful approach to business and risk and make their business operations and business practices more transparent.

In particular, data analytics tools help auditors access and interpret large amounts of data; and provide robust, factbased auditing results and quality audits, giving senior managers' confidence. Finance enhances reported numbers, and supports innovative approaches that lead to better and more comprehensive auditing procedures. The overall analysis of the data will help senior financial auditors and managers to obtain more accurate and timely audit results and to identify areas of potential fraud and business risk more quickly [28].

The results of the 12th hypothesis study show that audit analytics has a positive impact on the performance of internal audit. Audit analysis as a science for "discovering patterns, identifying anomalies, and extracting other useful information in basic or relevant data." The subject of auditing is through analysis, modeling and visualization in order to plan or perform an audit. (American Institute of Certified Public Accountants, 2015). According to Section 52 of the Standards on Auditing, analytical methods, such as analyzing and analyzing major ratios and trends, including the tracking of financial and non-financial fluctuations and relationships that are inconsistent with or deviate from other information, or are anticipated.

Based on the findings and findings of this study, the following suggestions are made: As the findings of this study show, the application of analytical methods in auditing accounting estimates is an effective method. Since these methods are simple and inexpensive to use in practice, it is recommended that audit firms apply some form of monitoring and quality control system to auditors and increase their auditors' knowledge in these cases through in-service training.

It is suggested that auditing courses in universities be given more attention to analytical methods and methods of auditing of audit estimates and teach students how to use these methods in practice. The audit process is changing from traditional to electronic. New information technologies have affected every aspect of the audit profession. Users of auditing services have newer needs, and only using these technologies can meet their needs, so auditors need to keep up with technology changes. The need to use audit analytics tools is a professional staff who often has the qualifications and requirements for the proper use of technical tools for auditing analysis. It is a periodic training of audit analysis tools.

Some analytics tools understand intuitive information easily, while others act as "black boxes" with implicit underlying methods. Auditors may prefer different analytical tools because of the conservative nature and limitations of the Code. Third, the extent to which the external auditor relies on the analytical results of internal auditors and whether internal auditors' analytical work can improve the quality of external audit is still unknown. Since internal auditors usually have frequent access to corporate or financial data, they can identify risks and exceptions in a timely manner using appropriate analysis.

Making data visible is only part of the job. Specific skills are needed to identify the target data, select information from the mass of data, and identify specific cases from the exceptions. Therefore, auditors need to have experience using data analytics tools. With the participation of the Assurance Services Executive Committee (ASEC) and the Audit Standards Board (ASB) Working Group, the theory and methodology researched in Radar helps formulate the American Association of Certified Auditors' Guide to Analyzing Audit Data, and the research findings on the growing use of data analysis tools in financial statement auditing and its implications for a set of auditing standards Provides standard formulation organizations.

Given the impact of applied analytical and quality auditing tools on internal audit performance, and according to its affiliate, it encourages auditing and management accounting and financial reporting committees to discuss the benefits of using data analytics tools. Auditors, talk to their auditors. In 
future studies, it is suggested to analyze the audits without ICT and to compare the two audits using ICT. It is also suggested that in future studies the role of information technology on aspects such as enhancing auditor knowledge, auditor independence, and so on will be explored. Finally, the auditing profession is currently assessing the many obstacles that may arise from the widespread use of data analytics tools derived from power technology, so it is recommended that future research address these barriers in a qualitative and quantitative way. The present research, like any other research, has some limitations, the most important of which was that it was not possible to contact and receive feedback through a questionnaire due to the inability to provide information to some staff and managers. Some of these employees and managers were transferred or retired to another organization, so there was no access to them.

\section{REFERENCES}

[1] Chen Y. and R. Leith, An Analysis of the Relative Power Characteristics of Analytical Procedures, Auditing: A Journal of Practice \& Theory, Fall 1999, pp. 35-69,

[2] PWC, 2012. Data Analytics How Data Analytics Can Help Internal Audit Better Understand Risk. Available at: https://www.pwc.com/en_US/us/industry/utilities/

publications/assets/pwc-utility-company-internal-audit-dataanalytics.pdf.

[3] Tawei Wang, Robert Cuthbertson; Eight Issues on Audit Data Analytics We Would Like Researched. Journal of Information Systems 1 March 2015; 29 (1): 155-162. doi https://doi.org/10.2308/isys-50955

[4] Cao, M., Chychyla, R., Stewart, T., 2015. Big data analytics in financial statement audits. Account. Horiz. 29 (2), 423-429.

[5] Rahimian, Nizamuddin (2007). Government audit and its types. Journal of Auditing Knowledge. No. 27.

[6] American Institute of Certified Public Accountants (AICPA), 2015 Audit Analytics and Continuous Audit: Looking Toward the Future. Available at: https:/www. aicpa.org/interestareas/frc/assuranceadvisoryservices/downloadabled ocuments/auditanalytics lookingtowardfuture.pdf.

[7] KPMG, 2012. Leveraging Data Analytics and Continuous Auditing Processes for Improved Audit Planning, Effectiveness and Efficiency. Available at: http:/www. kpmg.com/US/en/IssuesAndInsights/ArticlesPublications/Document s/data-analytics-continuous-auditing.pdf.

[8] Araj, F.G., 2015. Responding to Fraud Risk. The Institute of Internal Auditors Research Foundation (IIARF), Altamonte Springs, FL. http://dx.doi.org/10.1126/science. 1137840.

[9] Carcello, J.V., Eulerich, M., Masli, A., Wood, D.A., 2017. Do Internal Audits Reduce Operating, Financial Reporting, and Compliance Risk?.

[10] Deloitte, 2016. Internal Audit Analytics: The Journey to 2020, Audit Transformation Through Innovation and Technology. Available at: https://www2.deloitte.com/

content/dam/Deloitte/us/Documents/risk/us-risk-internal-auditanalytics-pov.pdf.

[11] Thiprungsri, S., Vasarhelyi, M.A., 2011. Cluster analysis for anomaly detection in accounting data: an audit approach. Int. J. Digit. Account. Res. 11.

[12] Kim, Y., Vasarhelyi, M.A., 2012. A model to detect potentially fraudulent/abnormal wires of an insurance company: an unsupervised rule-based approach. J. Emerging Technol. Account. 9 (1), 95-110.

[13] Jans, M., Alles, M., Vasarhelyi, M., 2014. A field study on the use of process mining of event logs as an analytical procedure in auditing. Account. Rev. 89 (5), 1751-1773.

[14] Teammate, 2012. Enhancing Audit Technology Effectiveness-Key Insights From TeamMate's 2014 Global Technology Survey. Available at: https://www teammatesolutions.com/WorkArea/DownloadAsset.aspx?id=107374 19044
[15] AuditNet, 2012. Survey of More Than 1,500 Auditors Concludes That Audit Professionals Are Not Maximizing Use of Available Audit Technology. Available at: http:// www.auditnet.org/publications/auditnet-news-november2012/auditnet-2012-state-of-technology-use-by-auditors-survey-ofmore-than-1500-auditorsconcludes-that-audit-professionals-are-notmaximizing-use-of-available-audit-technology.

[16] Braun, R.L., Davis, H.E., 2003. Computer-assisted audit tools and techniques: analysis and perspectives. Manag. Audit. J. 18 (9), 725731.

[17] Bierstaker, J., Janvrin, D., Lowe, D.J., 2014. What factors influence auditors' use of computer-assisted audit techniques? Adv. Account. 30, 67-74.

[18] Mahzan, N., Lymer, A., 2014. Examining the adoption of computerassisted audit tools and techniques: cases of generalized audit software use by internal auditors. Manag. Audit. J. 29 (4), 327-349.

[19] Lin, C.H., Shih, H.Y., Sher, P.J., 2007. Integrating technology readiness into technology acceptance: the TRAM model. Psychol. Mark. 24, 641-657.

[20] Cohen, A., Sayag, G., 2010. The effectiveness of internal auditing: an empirical examination of its determinants in Israeli organisations. Aust. Account. Rev. 20 (3), 296-307.

[21] IIA,2017. International Standards for the Professional Practice of Internal Auditing (Standards). The Institute of Internl Auditors (1220.A2).

[22] Sun, H., 2012. Understanding user revisions when using information system features: adaptive system use and triggers. Manag. Inf. Syst. Q. 36 (2), 453-478.

[23] Jasperson, J.S., Carter, P.E., Zmud, R.W., 2005. A comprehensive conceptualization of post-adoptive behaviors associated with information technology enabled work systems. MIS Q. 29 (3), 525557.

[24] Hiltz, S.R., Turoff, M., 1981. The evolution of user behavior in a computerized conferencing system. Commun. ACM 24 (11), 739 751.

[25] Compeau, D.R., Higgins, C.A., 1995. Application of social cognitive theory to training for computer skills. Inf. Syst. Res. 6 (2), 118-143.

[26] Ndubisi, N.O., Gupta, O.K., Massoud, S., 2003. Organizational learning and vendor support quality by the usage of application software packages: a study of Asian entrepreneurs. J. Syst. Sci. Syst. Eng. 12 (3), 314-331.

[27] Sarens G. \& I. Beelde, De 2006. "Interaction between internal auditors and the audit committee: An analysis of expectations and perceptions," Working Papers of Faculty of Economics and Business Administration, Ghent University, Belgium 06/357, Ghent University, Faculty of Economics and Business Administration.

[28] Moghaddam maenavi, Amir Hadi (2016). The future of auditing is the use of advanced analysis tools. Auditor's Journal.

[29] Ahmad Khodami, P., \& Muslim Saeedi, G. (2011). Investigating the effect of analytical methods results on auditors' efforts in auditing accounting estimates. Accounting and Auditing Research, 2011 (10). Retrieved from http://ensani.ir/en/article/227133 